\title{
RESEARCH ON ALGAE GROWING IN OPEN SYSTEM WITH CASCADE-TYPE INSTALLATION
}

\author{
Ancuta Nedelcu, Lucretia Popa, Iuliana Gageanu, Augustina Pruteanu \\ National Institute of Research-Development for Machines and Installations \\ Designed to Agriculture and Food Industry, Romania \\ nedelcuus@yahoo.com
}

\begin{abstract}
Algae represent an important natural resource that can be capitalized in the human economy being used in food, as organic fertilizers and as a raw material for the production of cosmetics, pharmaceuticals, alternative fuels, etc. The paper presents the results of the laboratory research carried out with a cascade type pilot installation for algae growing in open system. The installation typically has one or more transparent plane reactors, arranged in cascade, a collecting compartment, lighting system, stirring system, algal culture recirculation system to ensure the development conditions. Algae culture slips in a thin layer $(<40 \mathrm{~mm})$ on transparent panels that favour direct solar irradiance, easy heat dissipation, easy cleaning and maintenance. Bold Basal Medium (BBM) was used to ensure the culture with the nutrients needed for mineral nutrition and the concentration of the constituent substances was carefully monitored throughout the experiments. To study the algae culture growth rate, we measured and analysed mainly the cell density, dynamic viscosity, the $\mathrm{pH}$ of the nutrient medium, conductivity, turbidity, dissolved oxygen, salinity, determinations with a photospectrometer, under different environmental conditions created by the lighting regime and the ambient temperature. The research was aimed at obtaining algal biomass, considered renewable energy that provides biofuels, with a simple installation, by virtue of its construction, and adaptable to various environmental conditions.
\end{abstract}

Keywords: algal culture, biomass.

\section{Introduction}

Biofuels have come to the attention of the scientific world with the rise in oil prices, the need to ensure energy security and climate change concerns.

As noted in the European and national legislation on improving the quality of the environment as well as in literature [1-3]), it is desired to limit the quantity of fuel in the cultures and the orientation towards biofuels coming from non-food sources such as waste and algae [4].

One of the current directions in biological scientific research of a practical nature is algae cultivation for algal biomass production, considered an important raw material for producing alternative fuels (biogas, biodiesel, biobutanol, ethanol, etc.) [5-7]. The need for algae cultivation is substantiated by the benefits and the very good results obtained in the application of algal biomass in many fields. Another advantage of algal cultures is the immense amount of carbon dioxide that they can capture from the atmosphere [8].

According to the quantitative criterion, algal biomass accounts for about $20 \%$ of the world aquaculture production [9] and global algal biomass producers cultivate various species, depending on the purpose and the product obtained [10].

Industrial cultivation of algae has become widespread all over the world. According to estimates, of the 50,000 species of microalgae, about 10 are grown industrially in order to obtain commercially available products (Spirulina, Crypthecodiniumcohnii, Chlorella, Dunaliellasalina, Ulkenia sp., Haematococcuspluvialis, Schizochytrium, Aphanizomenonflos-aquae, Euglena and Odontellaaurita). Of the 10 industrially grown species, Chlorella, Spirulina and Cryptecodinium species have the largest contribution, as evidenced by the papers of the specialists in the field [9; 10].

Algae cultivation can be done under open conditions - in the field and closed conditions - in the laboratory, in freshwater or saline waters that cannot be used for agriculture.

For microalgal biomass production different culture systems are used: open, closed and hybrid. [11]. Although some industrial plants use closed tubular photobioreactors, most microalgal biomass units are based on open horizontal systems [12-14].

Algae cultivation under laboratory conditions has been proven to have advantages, characterized by the production of environmentally friendly products without impurities, which have been important in the context of environmental and health problems. 


\section{Materials and methods}

Algae cultivation technologies produced in monoculture include five distinctive stages. These stages include the selection and preparation of nutrient media, the preparation and inoculation of algae, the identification and observance of cultivation conditions followed by the selection and application of the appropriate cultivation method to obtain algal biomass used in various fields.

The installations for algae cultivation are mainly composed of: bioreactor, power sources, feeding systems, agitation systems, lighting systems, harvesting systems, workflow monitoring systems.

In order to obtain non-food raw materials for the production of biofuels, algae cultivation under laboratory conditions was studied in INMA laboratories using an open system installation, cascade type.

The "Installation for algae cultivation in open system, cascade type" (Figure 1), a functional model, consists mainly of one or more flat, open reactors arranged in cascade, a collecting compartment, lighting system, agitation system, algal culture recirculation system.

In this study, a thin-layer culture system was used. On the flat reactor, cascade type, made of transparent glass, plexiglass or polycarbonate panels, built in cascade, the algae culture slides in a thin layer favouring direct sunlight, easy heat dissipation, suspension agitation, gas exchange with the atmosphere, easy cleaning and maintenance.

The algal culture slides on the transparent panels in a thin layer of $3 \ldots 35 \mathrm{~mm}$, collected in a tank and recirculated with a submersible pump having a flow rate of $400 \mathrm{l} \cdot \mathrm{h}^{-1}$.

For the experimentation of algae cultivation technology with the open-system installation, of cascade type, we used the algae from Chlorella vulgaris species, strain code AICB 555, cultivated in the Bold Basal Medium (BBM).

The experiments presented were conducted in the period October 16-30, 2017, at ambient temperature, no heating sources being used for the enclosure or algae culture.

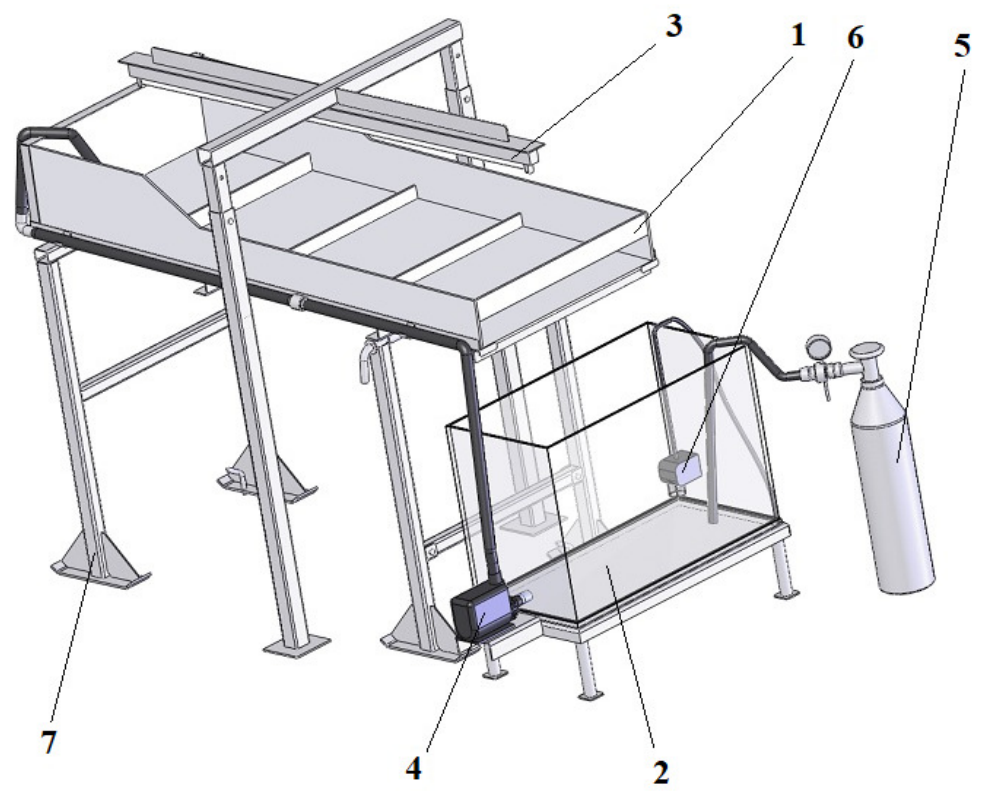

Fig. 1. Scheme of installation for algae cultivation in open system, cascade type: 1 - flat reactor (module); 2 - collecting compartment; 3 - lighting system; 4 - recirculation system; 5 - CO2 supply system and PH control; 6 - agitator

For the tests we used various measuring instruments and devices metrologically verified, adequately adjusted or calibrated.

In the 60 litre collecting tank, dilution of the Chlorella vulgaris inoculum was performed in 30 litres of BBM-Medium, and then the installation was put into operation. 
The agitation of the algae culture by recirculation (flow on the flat reactor) was carried out between 7:30 and 15:30 on weekdays, and during the rest of the time it was carried out in the collecting compartment by bubbling air.

Algae are capable of performing the photosynthesis process with the frequent pigment chlorophyll or phycocyanin. Thus, from water, mineral salts, $\mathrm{CO} 2$ using sunlight as the energy source and in the presence of chlorophyll green pigment synthesize organic substances.

Summing up the basic chemical reactions of photosynthesis results the following equation (1):

$$
\mathrm{CO}_{2}+2 \mathrm{H}_{2} \mathrm{O} \rightarrow\left(\mathrm{CH}_{2} \mathrm{O}\right)+\mathrm{O}_{2}+\mathrm{H}_{2} \mathrm{O} .
$$

An important factor affecting the photosynthesis process is light. As a result, during the experimentation light intensity was measured daily at 8,12 and 15 o'clock.

Also, the lighting regime influences the course and intensity of photosynthesis; during the day the flat reactor was additionally lighted with two fluorescent lamps, of $28 \mathrm{~W}$, each with a beam angle of 270 degrees.

In algal culture, the $\mathrm{pH}$ of the medium was maintained at values between 6 and 7 by injecting pure $\mathrm{CO}$. When limit values were exceeded, we added $\mathrm{HCl}$ if the $\mathrm{pH}$ increased and $\mathrm{NaOH}$ if the $\mathrm{pH}$ decreased. The acid/base was added drop by drop and the algal suspension was thoroughly agitated to homogenize before the next drop was added. Checks were performed using the $\mathrm{pH}$ meter HI 98100 at 8,12 and 15 o'clock.

Also, the density of the algal solution was measured on a daily basis using a hydrometer with measurement scale and the dynamic viscosity using a vibroviscosimeter with slides to see how much the viscosity of the algal solution increases over time (Figure 2). Also, on a daily basis, biomass was harvested by the filtration method and algal biomass was determined.

The density and viscosity measurement temperature, since there were no fluctuations in the ambient temperature, was considered constant. All utensils used were washed with distilled water and sterilized after each harvest.
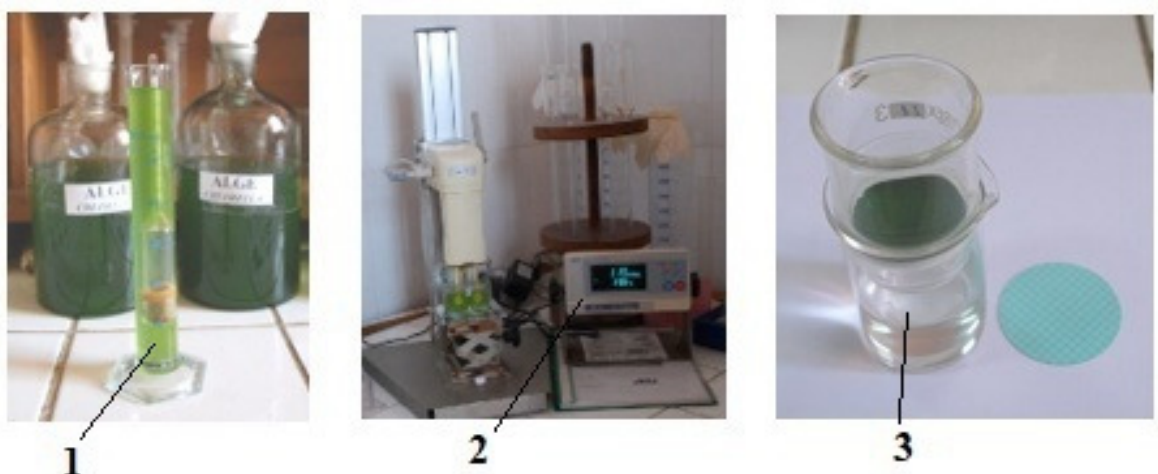

Fig. 2. Determining characteristics of algae culture: 1 - algal density using a hydrometer with measurement scale; 2 - dynamic viscosity by vibroviscosimeter with slides;

3 - algae harvesting by filtration

In order to determine the algal biomass, we did the following:

- $100 \mathrm{ml}$ samples of algal solution were harvested;

- the harvested samples were filtered through $4.5 \mu \mathrm{m}$ filters;

- the filters used were weighed before starting the filtration;

- the filters with retained algae were dried in the oven at $60^{\circ} \mathrm{C}$, for 4 hours;

- after being removed from the oven, the filters were kept in desiccator to ambient temperature and constant weight;

- the filters with retained algae were weighed and the mass obtained was calculated. 


\section{Results and discussion}

When the inoculum of Chlorella vulgaris algae was received, we made the following determinations:

- $\mathrm{pH}=6.5$;

- dynamic viscosity: $\eta=1.15 \mathrm{mPa} \cdot \mathrm{s}$ at $20.6^{\circ} \mathrm{C}$;

- density $\rho=1.0005 \mathrm{~g} \cdot \mathrm{cm}^{-3}$ at $20.6^{\circ} \mathrm{C}$;

- amount of biomass: $2.6272 \mathrm{~g}$ per $100 \mathrm{ml}$ solution.

Although the experiments with the "Installation for algae cultivation in open system, cascade type - ICA" (Figure 3) took place in a room, the lighting and temperature have varied continuously, depending on the weather. During cloudy days, the light intensity and air temperature were lower than on sunny days. As this has an impact on culture growth, the degree of lighting, temperature and humidity of the environment and the algae culture have been continuously recorded throughout the experiment and are shown in Table 1.
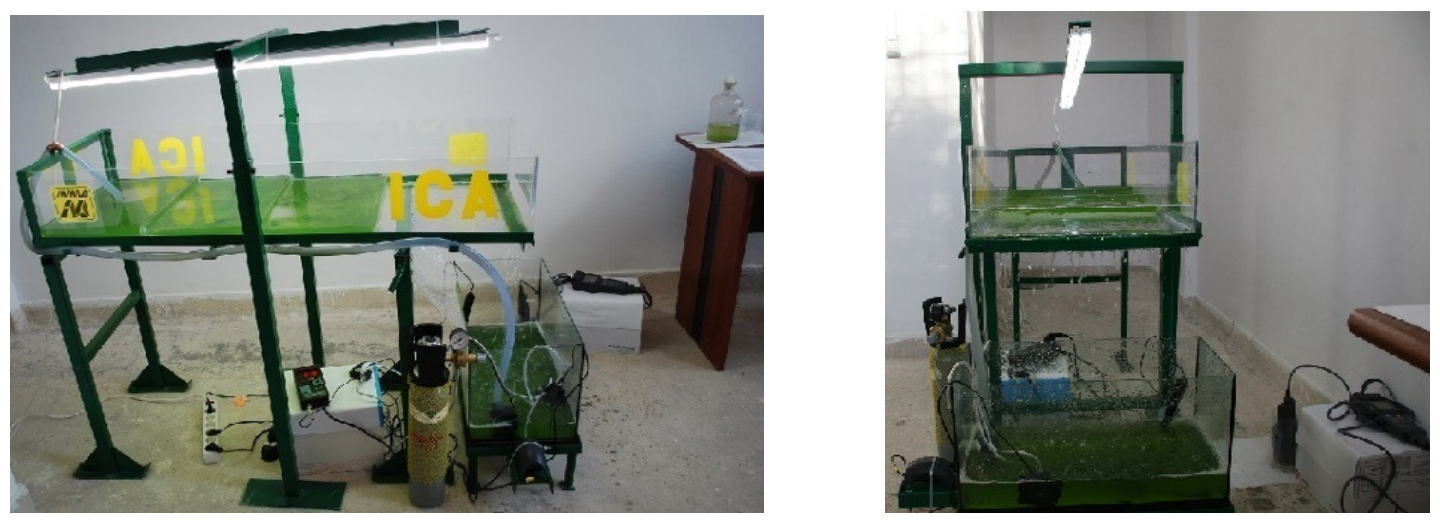

Fig. 3. Installation for algae cultivation in open system, cascade type during experiments

Table 1

Values recorded for the environmental parameters in the period October 18-30, 2017

\begin{tabular}{|c|c|c|c|c|c|c|c|c|c|c|c|c|}
\hline & \multirow{2}{*}{\multicolumn{3}{|c|}{$\begin{array}{c}\text { Temperature, } \\
{ }^{\circ} \mathrm{C} \\
\end{array}$}} & \multirow{2}{*}{\multicolumn{3}{|c|}{ Humidity, \% }} & \multicolumn{6}{|c|}{ Lighting level, lux } \\
\hline & & & & & & & \multirow{2}{*}{\multicolumn{3}{|c|}{$\begin{array}{c}\text { In the room } \\
\text { Recording time }\end{array}$}} & \multirow{2}{*}{\multicolumn{3}{|c|}{$\begin{array}{c}\text { In the flat reactor } \\
\text { Recording time }\end{array}$}} \\
\hline & \multicolumn{3}{|c|}{ Recording time } & \multicolumn{3}{|c|}{ Recording time } & & & & & & \\
\hline Date & 8 & 12 & 15 & 8 & 12 & 15 & 8 & 12 & 15 & 8 & 12 & 15 \\
\hline Oct.18 & 18.8 & 212 & 208 & & 4 & 65 & 194 & 2360 & 328 & 2430 & 3880 & 2730 \\
\hline & & 21.8 & & & & & 205 & & & & & \\
\hline & & 20. & & & & & 174 & 2400 & & & & \\
\hline Oct. & 19.2 & 20.3 & 2 & & 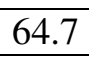 & & 180 & 653 & 80 & 500 & 26 & 2780 \\
\hline Oct.24 & 19.8 & 21.1 & 20.7 & 66.7 & 64.4 & 64.7 & 145 & 327 & 228 & 2630 & 2570 & 2490 \\
\hline Oct.2 & 18.4 & 20.4 & 21.1 & 62.4 & 61.3 & 60.3 & 164 & 1438 & 836 & 2830 & 3420 & 2980 \\
\hline Oct.26 & 15.3 & 15.8 & 15.5 & 71 & 690 & 66 & 203 & 367 & 280 & 2450 & 2650 & 2430 \\
\hline Oct. 2 & 15.3 & 15.3 & 16 & 70.5 & 72 & 70.5 & 219 & 371 & 280 & 2240 & 3670 & 2300 \\
\hline Oct.30 & 14.7 & 14.9 & 16 & 69.5 & 68.9 & 58.2 & 2870 & 500 & 388 & 3000 & 2710 & 2500 \\
\hline
\end{tabular}

Analysing the results, we can see that the temperature of the environment, where the experiments took place, registered an obvious decrease from the maximum value recorded at $21.8^{\circ} \mathrm{C}$ to a minimum of $14.7^{\circ} \mathrm{C}$, with effects on the temperature of the culture as shown in Table 2 .

Using the water quality meter U10, the following parameters were measured daily at 8, 12 and 15 o'clock: $\mathrm{pH}$, conductivity, turbidity, oxygen, culture temperature and salinity.

Analysing the results indicated in Table 2, we can see that the temperature of the environment, having values below $20^{\circ} \mathrm{C}$, influenced the temperature of the culture, the minimum value being $15^{\circ} \mathrm{C}$. However, by using the installation for algae cultivation in open system, cascade type (ICA) that provides culture agitation by recirculation and maintaining the nutrient medium recommended for the 
culture within the proposed limits and a pH with values between 6 and 7, some parameters recorded an increase in the value, which indicates culture development under these conditions (Figures 4 and 5).

Table 2

Values recorded for the algae culture parameters in the period October 18-30, 2017

\begin{tabular}{|c|c|c|c|c|c|c|c|}
\hline Date & Time & $\mathbf{p H}$ & $\begin{array}{l}\text { Conductivity, } \\
\mathrm{ms}^{\cdot} \mathrm{cm}^{-1}\end{array}$ & $\begin{array}{c}\text { Turbidity, } \\
\text { NTU }\end{array}$ & $\begin{array}{c}\text { Dissolved } \\
\text { oxygen, } \\
\text { mg }^{l^{-1}}\end{array}$ & $\begin{array}{c}\text { Temperature } \\
\text { in the culture, } \\
{ }^{\circ} \mathrm{C}\end{array}$ & $\begin{array}{c}\text { Salinity, } \\
\%\end{array}$ \\
\hline \multirow{2}{*}{ Oct. 18} & 7 & 6.5 & 1.02 & 245 & 3.27 & 18.5 & 0.04 \\
\hline & 15 & 6.5 & 1.03 & 420 & 3.93 & 19 & 0.04 \\
\hline \multirow{2}{*}{ Oct. 19} & 8 & 6.5 & 1.02 & 446 & 3.21 & 19 & 0.04 \\
\hline & 15 & 6.5 & 1.03 & 449 & 3.82 & 19 & 0.04 \\
\hline \multirow{2}{*}{ Oct. 20} & 8 & 6 & 1.04 & 457 & 2.98 & 18.5 & 0.04 \\
\hline & 15 & 6 & 1.02 & 511 & 3.92 & 19 & 0.04 \\
\hline \multirow{2}{*}{ Oct. 23} & 8 & 6.5 & 1.08 & 495 & 3.93 & 18.5 & 0.04 \\
\hline & 15 & 7 & 1.05 & 619 & 3.86 & 18.3 & 0.04 \\
\hline \multirow{2}{*}{ Oct. 24} & 8 & 6.25 & 1.06 & 619 & 2.19 & 18 & 0.04 \\
\hline & 15 & 6.5 & 1.08 & 674 & 3.88 & 17.8 & 0.04 \\
\hline \multirow{2}{*}{ Oct. 25} & 8 & 6.75 & 1.06 & 630 & 2.59 & 16.5 & 0.04 \\
\hline & 15 & 6.5 & 1.07 & 760 & 3.43 & 17.5 & 0.04 \\
\hline \multirow{2}{*}{ Oct. 26} & 8 & 6.25 & 1.11 & 759 & 3.12 & 16 & 0.04 \\
\hline & 12 & 6.25 & 1.11 & 607 & 4.09 & 16.5 & 0.05 \\
\hline \multirow{2}{*}{ Oct. 27} & 8 & 6.5 & 1.12 & 719 & 3.55 & 16 & 0.04 \\
\hline & 12 & 6 & 1.12 & 808 & 3.97 & 15.5 & 0.05 \\
\hline Oct. 30 & 8 & 7 & 1.15 & 595 & 3.81 & 15 & 0.05 \\
\hline
\end{tabular}

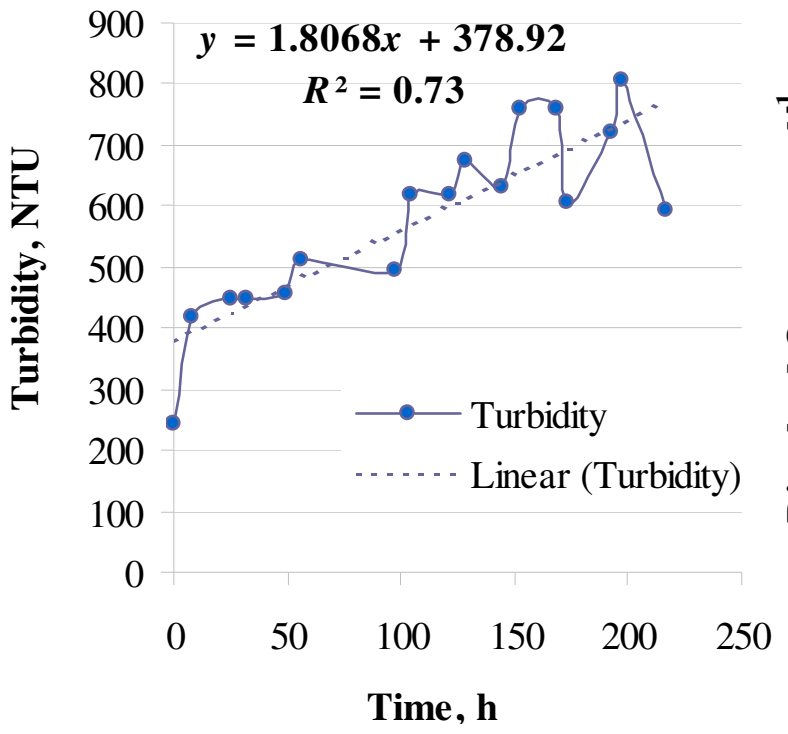

Fig. 4. Algae culture turbidity

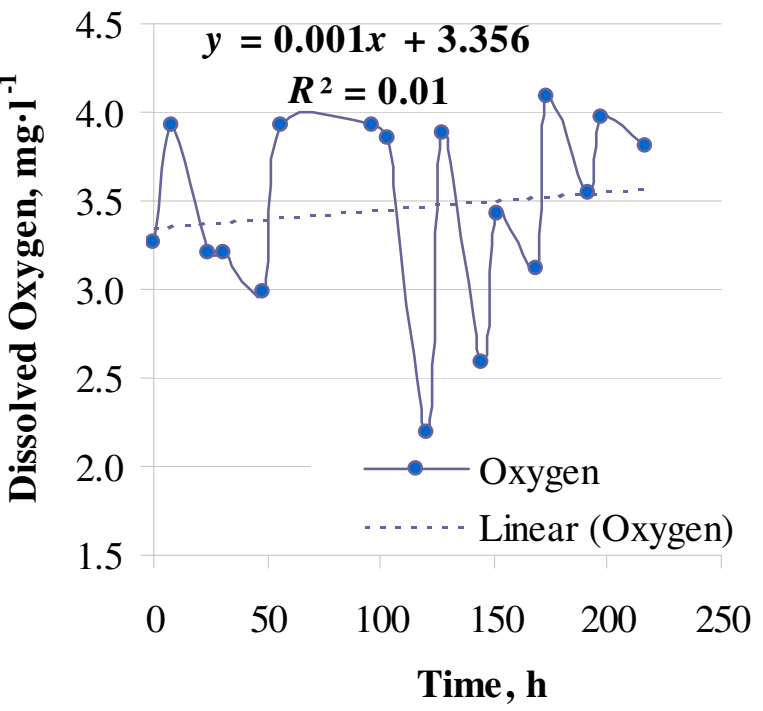

Fig. 5. Culture dissolved oxygen

Also, during algae cultivation tests, using the open system installation, a harvest of the algae culture was performed daily and the dynamic viscosity, density and algal biomass were determined.

The results obtained in the algae cultivation using ICA installation, at ambient temperature and without heating the algae culture, can be identified in Table 3:

- the density of the algae culture was constant around the value of $1.003 \mathrm{~g} \cdot \mathrm{cm}^{-3}$;

- the biomass obtained in the period October $18-30$ increased from $0.0188 \mathrm{~g} \cdot(100 \mathrm{ml})^{-1}$ to $0.03 \mathrm{~g} \cdot(100 \mathrm{ml})^{-1}$;

- for algae culture dynamic viscosity were recorded values that oscillated between 1.35 and $1.5 \mathrm{mPa}$ s, influenced by ambient temperature. 
Values recorded for the algae culture density, biomass and dynamic viscosity

in the period October 18-30, 2017

\begin{tabular}{|c|c|c|c|c|c|c|c|}
\hline \multirow{2}{*}{ Parameter } & \multicolumn{7}{|c|}{ Operating time, hours } \\
\cline { 2 - 8 } & $\mathbf{2 5}$ & $\mathbf{4 9}$ & $\mathbf{9 7}$ & $\mathbf{1 2 1}$ & $\mathbf{1 4 5}$ & $\mathbf{1 6 9}$ & $\mathbf{1 9 3}$ \\
\hline Density, $\mathbf{g} \cdot \mathbf{c m}^{\mathbf{3}}$ & 1.003 & 1.003 & 1.003 & 1.003 & 1.003 & 1.003 & 1.001 \\
\hline Biomass, $\mathbf{(} \cdot \mathbf{1 0 0} \mathbf{~ m l} \mathbf{~}^{-\mathbf{1}}$ & 0.0188 & 0.0322 & 0.0322 & 0.03 & 0.0294 & 0.031 & 0.0276 \\
\hline Dynamic viscosity, $\mathbf{m P a} \cdot \mathbf{s}$ & 1.5 & 1.44 & 1.5 & 1.34 & 1.35 & 1.35 & 1.4 \\
\hline
\end{tabular}

In collaboration with the ISB Bucharest faculty, the following determinations were made for algae culture:

- algae cell counting - made by a counting chamber microscope resulting in $5 \cdot 10^{6}$ cells $\cdot \mathrm{ml}^{-1}$.

- cell density measurement - made by a spectrophotometer T90+ PG at750 nm wavelength;

Chlorophyll absorption spectrum in the visible field was recorded between $380 \mathrm{~nm}$ and $800 \mathrm{~nm}$ for the acetone extract.

Table 4

Values recorded for the cell number and optical density

\begin{tabular}{|c|c|c|c|}
\hline \multirow{2}{*}{ Parameter } & \multicolumn{2}{|c|}{ Date } \\
\cline { 3 - 4 } & Oct. 25 & Oct. 30 \\
\hline \multicolumn{2}{|c|}{ Algae cells counting, cells $\cdot \mathrm{ml}^{-1}$} & $5 \times 10^{6}$ & $6 \times 10^{6}$ \\
\hline \multirow{2}{*}{ Absorption } & $660 \mathrm{~nm}$ wavelength & 0.256 & 0.592 \\
\cline { 2 - 4 } & $434 \mathrm{~nm}$ wavelength & 0.548 & 1.506 \\
\hline
\end{tabular}

The values in the table clearly indicate that, although algae cultivation was carried out in an environment where the temperatures did not fall within the recommended range of $22 \ldots 25^{\circ} \mathrm{C}$ [8], Annex 3, the algae culture developed progressively, linearly by providing the proper nutrient medium, monitoring and correcting the $\mathrm{pH}$ of the culture, and agitating it by recirculation using the installation for algae cultivation in open system, cascade type, ICA.

\section{Conclusions}

1. Currently, biomass obtained from energy plants is criticized because these plants require large areas for cultivation, thus competing with the agricultural areas allocated for food production.

2. One of the current directions of biological scientific research of a practical nature is algae cultivation for algal biomass production, and the use as non-food raw material for alternative fuels production.

3. The technology for obtaining advanced biofuels from non-food bio-resources, such as algae, is made up of several technological processes carried out with special installations and technical equipment.

4. The installation for algae cultivation in open system, cascade type, proposed, is intended for carrying out laboratory researches for the cultivation of algae species in an open system, in various nutrient media and cultivation conditions: light, temperature, agitation.

5. The installation is built mainly from one or more open flat reactors, on which the algae culture slides in a thin layer favouring direct sunlight, easy heat dissipation, easy cleaning and maintenance. The advantage of these thin-layer systems is the achievement of high biomass density and high productivity due to the high surface-to-volume ratio.

6. The results of the experiments carried out in an environment, where the temperatures did not fall within the recommended range of $22 \ldots 25^{\circ} \mathrm{C}$, proved that by providing the proper nutrient medium, monitoring and correcting the $\mathrm{pH}$ of the culture, agitating it by recirculation (specific to the installation) the algae culture can develop progressively, linearly.

7. The research was aimed at obtaining algal biomass, considered renewable energy that provides biofuels, with a simple installation, by virtue of its construction, and adaptable to various environmental and production conditions. 


\section{Acknowledgements}

The research work was funded by the NUCLEU Programme of the Ministry of Research and Innovation, through financing contract no. 8 N / 09.03.2016-Act.Ad.2/2017for the project " $P N 1624$ 0404 ,Researches regarding the development of an innovative technology for obtaining advanced biofuels from non-food bio-resources.

\section{References}

[1] Carăuş I. Algae culture for biomass and active principles: Course notes, laboratory work. Bacau University, Romania, 2007. 99 p.

[2] Pavnutescu M., Exclusively GR: Green oil from sea algae. Green Report. 2011, [online] [28.11.2011]. Available at: http://www.green-report.ro/exclusiv-grnbsppetrol-ldquoverderdquodin-alge-marine/.

[3] Pecingina I.R., Biotechnology for Obtaining Alternative Fuels from Seaweed. Annals of the "Constantin Brâncuşi”" University of Targu Jiu, Engineering Series, Issue 3, 2011, pp. 418-426.

[4] Anghelet A., Nedelcu A., Mircea C., Zaica A. Dumitru D., Cristescu A. Modern Technologies of Algae Biomass Using for Obtaining Alternative Fuels.ISB-INMA TEH Agricultural Engineering Journal, 26-28 October 2017,Bucharest,pp. 561- 568.

[5] Şumălan R. BIOMASA-Sursă de energieregenerabilă, Gazeta de agricultură (Biomass-source of renewable energy. Agriculture Journal), [online] [18.04.2011], Available at: https://www.gazetadeagricultura.info/eco-bio/565-energie-regenerabila/11375-biomasa-sursa-deenergie-regenerabila.html.

[6] Farieda M., Samera M., Ábdelsalam E., Yousef R.S., Attia Y.A., Ali A.S. Biodiesel production from microalgae: Processes, technologies and recent advancements, Renewable and Sustainable Energy. Reviews 79,2017, pp. 893-913.

[7] Alternative fuels: biodiesel from algae Tag Archives: algaculture for fuel, [online] [03.11.2011]. Available at: http://inimafericita.ro/tag/cultivarea-algelor-pentru-combustibil/.

[8] Beverley M., Freeway Algae Garden Turns CO2 Emissions into Energy in Switzerland, [online] [11.03.2014]. Available at: http://inhabitat.com/overpass-algae-garden-turns-co2-emissions-intocombustible-biomass-in-switzerland/.

[9] Dobrojan S., Şalaru V., Melnic V., Dobrojan G. Algae culture, Monography. State University from Moldavia, Laboratory of Scientific Research “Algology”, 2016, Chişinău.

[10]Egardt J., Lie O, Aulie J., Myhre P. Microalgae a market analysis carried out as part of the Interreg KASK IVA project: Blue Biotechnology for Sustainable Innovations, "Blue Bio",2013, Sweden $79 \mathrm{p}$.

[11] Nedelcu A., Covaliu C., Popa L., Ciuperca R., Anghelet A., Zaica A., Costin M., Technologies and installations designed to industrial scale cultivation of microalgae for obtaining algal biomass, ISB-INMA TEH Agricultural Engineering Journal, 26-28 October 2017, Bucharest pp. 463-468.

[12] Apel A.C., Pfaffinger C.E., Basedahl N., Mittwollen N., Göbel J., Sauter J., Brück T., WeusterBotz D., Open thin-layer cascade reactors for saline microalgae production evaluated in a physically simulated Mediterranean summer climate. Algal Research, Issue 25, 2017,pp.381-390.

[13] Marchin T., Erpicum M., Franck F. Photosynthesis of Scenedesmus obliquus in outdoor open thin-layer cascade system in high and low CO2 in Belgium, Journal of Biotechnology, Issue 215, 2015, pp.2-12.

[14]Zittelli G.C., Biondi N., Rodolfi L., Tredici M. R.,Photobioreactors for Mass Production of Microalgae, In: Handbook of Microalgal Culture. Ed. By A. R. P. D. Emeritus and Q. H. Ph.D. John Wiley \& Sons, Ltd,2013, pp. 225-266. 